\title{
Binocular integration in line rivalry
}

\author{
JOSEPH D. ANDERSON \\ University of Wisconsin, Madison, Wisconsin 53706 \\ and \\ HAROLD P. BECHTOLDT and GREGORY L. DUNLAP \\ University of Iowa, Iowa City, Iowa 52242
}

\begin{abstract}
Three experiments investigated the frequency of a monocular, partial binocular, or nearly total binocular report of dichoptically presented stimuli in a line rivalry paradigm. The consistently important variable was the duration of the presentation time of the stimuli, which ranged from 50 to $1,100 \mathrm{msec}$, with each experiment covering only a portion of these times. Variations in equipment, instructions, response mode, light intensity, and position in the visual field were introduced. The main result was a report of fusion of the binocular inputs, with little or no suppression for about $40 \%$ to about $80 \%$ of the foveal presentations of $100 \mathrm{msec}$ or less, the percentage varying over the three experiments. Partial fusion (some, but not all, lines crossed) was indicated in another $40 \%$ or more of the reports. Lateral positioning of the stimuli $6 \mathrm{deg}$ from the fixation point, but not at $3 \mathrm{deg}$ or less, resulted mainly in reports of monocular inputs. The possibility, and serious implication for studies of rivalry phenomena, of range effects (Poulton) from the within-subjects variation of duration of stimuli was noted.
\end{abstract}

In the usual "real-world" viewing situations, we observe through our eyes two disparate views, yet phenomenally we experience a single view. Two contrasting explanations of this fact have developed, each with its advocates. The more recent is a suppression theory (Asher, 1953; Fox \& Check, 1966; Hochberg, 1964; Kaufman, 1974; Ogle, 1962; Verhoeff, 1935) which claims that some form of suppression of the input of one eye by the stimuli presented to the other eye is the normal state of affairs. The older explanation invokes a fusion process (Galen, Alhazen, Descartes, \& Newton, as noted by Lindberg, 1976); this theory has modern proponents of a version (Bishop \& Henry, 1971; Boring, 1933, 1963; Dodwell, 1970; Julesz, 1971; Sperling, 1970) in which the images from the two eyes are considered as fused in some fashion.

The selection of one of the theories over the other represents a parsimonious theoretical posture, but one that may not accord with the facts of nature. As was the case with the two main theories of color vision, both contrasting views of binocular vision may be correct in some situations (Fox \& McIntyre, 1967; Goldstein, 1970; Ono, Angus, \& Gregor, 1977; Pettigrew, 1972);

While the two states of fusion and suppression at any one retinal point are mutually exclusive, the relative independence of separate foveal receptive fields at one time and at the same receptive field at two separate times provides ample opportunity for both processes to be involved in reported phenomenal views. Support for both views was reported by Goldstein (1970); in one of his experiments, a $500-\mathrm{msec}$ stimulus duration consisted of a horizontal line presented to one eye and a vertical line to the other. Goldstein reported an average of over

Send reprint requests to J. D. Anderson, Communication Arts Department, University of Wisconsin, Madison 53706.
$70 \%$ nonsuppressed reports with a 1 -deg stimulus, but with marked individual differences. He concluded that, with simultaneous dichoptic presentation of line rivalry designs, suppression can be demonstrated on only some of the trials (1970).

The momentary presentation paradigm used by Goldstein provides useful data regarding the possibility of a sequence of neural processes such as a fusional state followed by an inhibitory state associated with suppression. Under systematic variation of the duration of stimulus presentations, the frequency of fusion and suppression reports may show progressive changes. Such results are suggested by the microelectrode recordings of the responses of single cortical cells to a variety of stimulus designs in the cat and monkey (Hubel \& Wiesel, 1965, 1970; Pettigrew, 1972). Pettigrew (1972) suggests the firing of single cortical units in the presence of disparate stimuli represents the fusion of two monocular inputs. The responses of single cortical cells to depth stimuli clearly shows an inhibitory or suppression operation (Bishop \& Henry, 1971). Of course, we cannot generalize directly from animal data to human processing, nor assume an isomorphism between cortical processes and phenomenal experience in human visual perception.

Our experiments used the momentary presentation paradigm to investigate the relationship between stimulus duration and the phenomenal report of monocular or binocular stimuli. To provide evidence of the generality of the results, variations were also introduced in types of apparatus, instructions, response mode, location in the visual field, light intensities, and experimenters.

\section{EXPERIMENT 1}

The initial responses to rival line stimuli at five durations were recorded by subjects sketching their 
percepts. The number of crossing lines in each drawing provided the dependent measure.

\section{Method}

Subjects. The subjects were 36 male and female students from an introductory psychology class who were screened for normal visual acuity, or acuity corrected to normal by contact lens, and for balanced acuity between the two eyes by means of an orthorater.

Apparatus. A modified Scientific Prototype three-field tachistoscope, Model GB, was employed. Fields 1 and 2 were used to present simultaneously to both eyes pairs of three-line patterns, each drawn in India ink on white bristol board. Polarized filters restricted each member of the stimulus pair to only one eye. Field 3 of the tachistoscope provided both a fixation point and a constant illumination between presentations. Each stimulus pattern consisted of two concentric circles with three parallel lines tilted at 45 or $135 \mathrm{deg}$ within each inner circle. In each presentation the stimulus patterns were arranged so that a set of three lines presented to one eye was oriented 90 deg to the set presented to the other eye. On a pseudorandom half of the trials, stimuli presented to the right eye were at $45 \mathrm{deg}$ but at $135 \mathrm{deg}$ on the other half of the trials. The inner circle containing the lines subtended $1 \mathrm{deg}$ of visual angle at the subject's eye, while the outer circle had a 3-deg diam. Brightness of the three fields, measured at the eyepiece by a Textronix photometer with a $\mathrm{J} 6503$ probe, was $.3 \mathrm{fL}$ in one condition and $1.2 \mathrm{fL}$ in the other.

Procedure. Subjects were shown drawings of the stimuli as well as a composite of both sets of lines in a cross-hatched pattern. The patterns including rivalry were demonstrated. The subjects were instructed to immediately report the first pattern they saw by drawing (with a pencil) on a response form provided by the experimenter a facsimile of the pattern. For each trial the subject was instructed to blink, look at the fixation dots, and push the start button to initiate the stimulus presentation. Each subject received eight trials at randomly ordered presentations of each of the five times of $50,75,100,200$, and $400 \mathrm{msec}$. Stimuli were presented in the center of the subject's field of vision and 2 deg to the left and right of center.

\section{Results and Discussion}

A four-factor design was employed with two within variables and two between variables. The between variables were stimulus brightness $(.3 \mathrm{fL}$ or $1.2 \mathrm{fL})$ and position of the stimulus in the subject's field of vision ( $2 \mathrm{deg}$ left, center, $2 \mathrm{deg}$ right). The within variables were the stimulus presentation times $(50,75$, 100,200 , and $400 \mathrm{msec}$ ) and the first half of the presentation sequence compared to the second half. For each presentation of the stimulus, the subject's pencil drawing of the configuration of lines which he had seen first was scored according to the number of evident crossed lines. If none of the two sets of three lines was crossed, the trial was scored. If one of a set crossed all three lines of the other set, the score was 1 . If two lines crossed all three of the other set, a score of 2 was assigned. If all three lines of one set crossed all three lines of the other set, a maximum score of 3 was assigned; a higher score represented a greater degree of phenomenal fusion. An analysis of variance for this measure revealed significant effects only for presentation time $[\mathrm{F}(4,31)=20.53, \mathrm{p}<.01]$.

The results summarized in Table 1 are consistent with the suggestion that the visual system, even at very brief presentation times, may resolve the inputs from both eyes by the suppression of the input of one eye (no crossing lines), a partial mosaic of the inputs of both eyes (one or two crossing lines), or a more nearly totally fused input from both eyes (three crossing lines). The fact that the entire input from both eyes can result in a grid percept of six crossing lines (three in each direction), even if for only a portion of the trials, casts grave doubts upon the notion that no phenomenal fusion of binocular inputs exists in a rivalry condition. The data in Table 1 imply that binocular fusion is a primary state of human binocular vision and that the reported mosaic patterns may be described as partial fusion, or incomplete suppression of fused binocular inputs.

That subjects reported $43 \%$ fused stimulus patterns at the 50 -msec presentation time and only $18 \%$ fused patterns at $400 \mathrm{msec}$ indicates the onset of rivalry at the longer presentation time, which apparently masked the initial (i.e., fused) pattern percept. The sharp decline in reports of fusion between presentations for 200 and $400 \mathrm{msec}$ indicates the initial fusion often gave way to rivalry alternations between 200 and $400 \mathrm{msec}$.

\section{EXPERIMENT 2}

The range of stimulus durations was extended to $800 \mathrm{msec}$ since a considerable number of binocular percepts were reported at $400 \mathrm{msec}$ in Experiment 1. The response measure was frequency of pushing each of three response buttons.

\section{Method}

Subjects. The subjects were 15 volunteers recruited from university classes who were screened for normal visual acuity and for balanced visual acuity between the two eyes.

Apparatus. A Gerbrands three-field projection tachistoscope interfaced with a PDP-12 computer was used to present stimulus patterns similar to those of Experiment 1. Responses were restricted to pushing one of three buttons labeled with three lines at 45 or $135 \mathrm{deg}$ or with six lines in a cross-hatched pattern.

Procedure. As in Experiment 1, subjects were shown the rivalry stimuli and then instructed as to the response buttons; they were to report both their first percept and a second one if the stimulus pattern changed. Stimuli were presented at the center of the field or $3 \mathrm{deg}$ on each side; appropriate fixation points were provided. Stimulus brightness measured by a Textronix photometer with a J 6503 probe was $.8 \mathrm{fL}$ at the subject's eye.

\section{Results and Discussion}

Because subjects tended to report only one percept following stimulus initiation, only first responses were scored. An analysis of variance of the number of binocular (cross-hatched) responses revealed only one

Table 1

Percent of Total Responses in Three Categories for Each of Five Stimulus Durations

\begin{tabular}{lccccc}
\hline \multirow{2}{*}{$\begin{array}{c}\text { Response Class } \\
\text { and Name }\end{array}$} & \multicolumn{5}{c}{ Stimulus Duration (in msec) } \\
\cline { 2 - 6 } & 50 & 75 & 100 & 200 & 400 \\
\hline Three crossed lines* & 43 & 41 & 39 & 40 & 18 \\
One or two crossed lines** & 37 & 41 & 31 & 26 & 29 \\
No crossing lines $\dagger$ & 20 & 18 & 30 & 34 & 53 \\
\hline
\end{tabular}

*Binocular **Binocular Mosaic tMonocular 
significant effect, that of presentation time $[F(5,14)=$ $3.03, \mathrm{p}<.05]$. Over all trials, subjects gave $72 \%$ binocular responses, with $79 \%$ binocular responses at $50 \mathrm{msec}, 77 \%$ at $75 \mathrm{msec}, 78 \%$ at $100 \mathrm{msec}, 63 \%$ at $200 \mathrm{msec}, 78 \%$ at $400 \mathrm{msec}$, and $55 \%$ at $800 \mathrm{msec}$. These percentages show a trend similar to the findings of Experiment 1 if the categories of binocular mosaic and fused binocular reports in that experiment are combined into a single binocular report category; however, the break in the function appeared between 400 and $800 \mathrm{msec}$ rather than between 200 and $400 \mathrm{msec}$. As in Experiment 1, subjects tended to report binocular percepts as the image seen first, especially at shorter presentation times. At longer presentation times, the onset of rivalry alternations apparently tended to mask the initial percept in spite of instructions to report both the first pattern seen and a second pattern if one occurred.

\section{EXPERIMENT 3}

Since Experiment 2 indicated a large percentage of binocular responses at $800 \mathrm{msec}$, the times were extended to 900 and $1,100 \mathrm{msec}$. The response measure was the frequency of two classes of verbal responses dealing with possible changes in the phenomenal percepts.

\section{Method}

Subjects. The 15 male and female subjects were from an introductory psychology class and were screened for normal visual acuity and balanced acuity as in the other experiments.

Apparatus. Stimuli, similar to those of Experiments 1 and 2, were presented by a Compco stereo projector modified for 50-W lamps. A solid state timer controlled the stereo projector and a fixation masking-field projector. Brightness of the projector fields was measured at $5 \mathrm{fc}$ at the subject's eye by a Textronix photometer with a J 6501 probe.

Procedure. The stimuli and rivalry were demonstrated and the subjects instructed to report verbally the stimulus pattern seen first and, if the pattern seemed to change, to report also the second pattern. Stimuli were presented at the center of the subject's field at the fixation point or at $6 \mathrm{deg}$ to the right and left of center. A pseudorandom sequence provided 10 trials at each of the six stimulus durations of $100,300,500,700,900$, and $1,100 \mathrm{msec}$; half the stimuli to the right eye were tilted at $45 \mathrm{deg}$ and the other half at $135 \mathrm{deg}$.

\section{Results and Discussion}

Subject's responses were scored for (1) the number of crossed-first responses and (2) the number of crossedonly responses. The first measure indicated whether a subject's initial perception was of both sets (i.e., input from both eyes) or only one set of lines (i.e., input from only one eye). If the initial perception was binocular, the second measure indicated the distribution of latencies between the initial presentation of the stimuli and the onset of rivalry.

A separate analysis of variance was carried out for the two dependent measures. For the crossed-first measure, a significant main effect was found for stimulus position in the visual field $[\mathrm{F}(2,14)=21.96, \mathrm{p}<.01]$. For the crossed-only measure, significant results were obtained for position in the visual field $[\mathrm{F}(2,14)=21.41$, $\mathrm{p}<.01]$ and for stimulus presentation times $[\mathrm{F}(2,14)=$ $8.66, p<.01]$. The last result is consistent with those reported in Experiments 1 and 2 regarding presentation times. In the present study, since subjects were instructed to report not only the pattern they perceived first but also the first rivalry alternation, it is possible to estimate the duration of the initial fusion. Over all field positions combined, subjects reported cross-hatched patterns in $56 \%$ of the total trials. They reported no change in these patterns in $40 \%$ of the trials at $100 \mathrm{msec}$, in $27 \%$ at $300 \mathrm{msec}$, in $23 \%$ at $500 \mathrm{msec}$, in $15 \%$ at 700 and $900 \mathrm{msec}$, and in $13 \%$ at $1,100 \mathrm{msec}$.

It is apparent that for all conditions combined there were far lower percentages of binocular responses than in the first two experiments. The reason becomes clear when one considers the effect of presenting the stimuli $6 \mathrm{deg}$ to the left and right of center rather than 2 or $3 \mathrm{deg}$ as in the first two experiments (an effect that may have been enhanced by the much greater brightness value in the present experiment). The mean number of crossed-first responses, with a possible count of 10 , was 9.17 for stimuli presented in the center of the subject's visual field, 4.20 for presentations 6 deg to the left, and 3.40 for 6 deg to the right, as shown in Figure 1. While subjects gave binocular reports in $95 \%$ of the trials for stimuli presented in the center of the visual field, for stimuli presented 6 deg to the left or right of straight ahead the percentages of crossed-first responses were only $42 \%$ and $34 \%$, respectively. In approximately $60 \%$ or more of the trials in which the stimuli were presented off center, subjects reported an initial percept which corresponded to only one of the monocular inputs.

\section{GENERAL DISCUSSION}

Considerable variability was found both between experiments and between subjects within each experiment. Goldstein (1970) also reported extensive variation between subjects. These results suggest that the mechanisms of binocular vision are extremely sensitive to variations in experimental conditions such as brightness, duration, and position of the stimulus in the visual field; in addition, subjects are probably very susceptible to

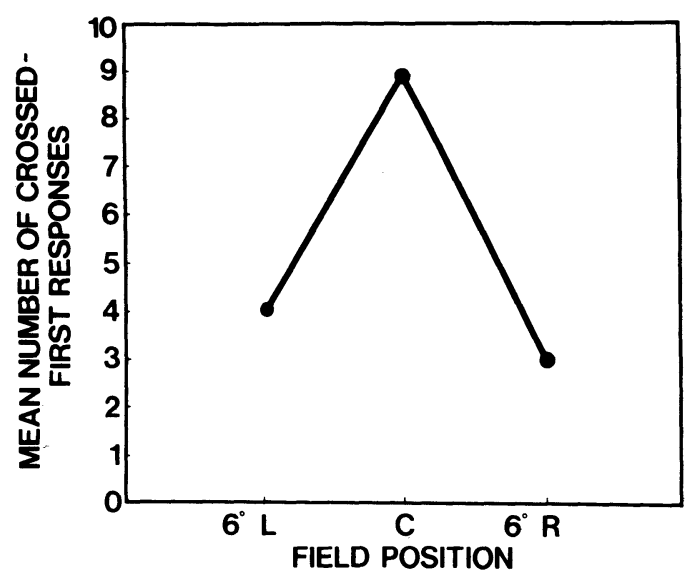

Figure 1. Mean number of crossed-first (binocular) responses for each field position. 
demand characteristics of the various response modes and vary greatly in their perceptual mechanisms.

The clear and persistent finding in all our work, however, is that briefly presenting rival line stimuli (of 1-deg visual angle) to the center of the subject's field of vision leads to reports of phenomenal fusion of the two sets of lines, with little or no suppression at the intersections in a large number of trials. The frequency of such reports ranged from approximately $40 \%$ to about $79 \%$ of the trials at $100 \mathrm{msec}$ or less in the different experiments. In another $30 \%-40 \%$ of the reports, partially crossed line patterns were indicated, while only $20 \%$ or so of the reports suggested uncrossed lines corresponding to one of the monocular inputs. Subjects simply asked to report verbally what they saw, reported a cross-hatched pattern in as many as $90 \%$ of the trials. These results are generally in agreement with the over $70 \%$ fusion responses reported by Goldstein at $500 \mathrm{msec}$ (1970).

Across all experiments the major factor influencing subject report was the stimulus duration. There were consistently far more reports of crossed and partially crossed lines at shorter presentation times than at longer times. One implication is staged processing of binocular inputs. The short presentation times isolate to some degree the initial stages, and the longer presentation times allow subsequent stages to occur. Although reports of complete fusion of both monocular inputs were not always in the majority, the fact that total binocular fusion was experienced in many cases under the extreme rivalry conditions imposed suggests that the initial state of binocular integration may be one of phenomenal fusion of the separate binocular inputs, and that suppression of one of the inputs occurs secondarily. Indeed, although no firm and consistent threshold of rivalry latency was found, it appears from our data that the onset of rivalry tends to occur for many subjects at between 200 and $400 \mathrm{msec}$ after onset of the stimulus (for stimuli presented to the center of the subject's visual field). It should be noted that, in Experiment 3, initial fusion was sutained throughout the $1,100-\mathrm{msec}$ stimulus presentation on $13 \%$ of the trials. On most of the trials, however, the visual system apparently resolved the conflicts inherent in the fused image resulting from the divergent monocular stimulus patterns by suppressing, probably through lateral inhibition, one member of each conflicting set of inputs. Such an explanation is not inconsistent with studies of the neurophysiological processing of visual stimuli in cats and monkeys. Blakemore, Carpenter, and Georgeson (1970) have also reported psychophysical evidence for lateral inhibition between orientation detectors in the human visual system; the present study seems to provide additional evidence for such inhibition.

The noticeable variation in the estimated rivalry onset times across experiments may have been created by the intentional changes in equipment, populations sampled, instructions, and experimenters introduced to establish the stability of any fusion-suppression phenomena. An alternative explanation, however, is that this variation, at least in part, arises from the range effect associated with the within-subjects design for the variation in stimulus duration; in each experiment, the monocular report tended to occur more frequently at the longest stimulus presentations regardless of the absolute time value. This explanation can be tested by repeating one or more of these experiments with duration of stimulus presentation as a betweensubjects variable. The existence of a marked change in rivalry onset associated with a change from a within- to a betweensubjects design would have serious implications for the interpretation of existing investigations of phenomenal rivalry. The possibility of such range effects in within-subjects designs of perceptual problems has been emphasized by Poulton (1973).

While presenting the stimuli just off center $(2$ or $4 \mathrm{deg})$ seemed to have little effect upon subject responses in Experi- ments 1 and 2, the presentation of stimuli 6 deg to the left and right of center of the subject's visual field in Experiment 3 led to a marked increase in the number of reports of a single monocular input. Apparently, a factor such as eye position or retinal displacement resulted in such imbalances in the integrative mechanisms that nearly complete suppression of one of the monocular inputs was achieved. These results are consistent with unpublished reports showing dominance of stimuli in the temporal visual field (Bechtoldt \& Colliver, Note 1).

\section{REFERENCE NOTE}

1. Bechtoldt. H. P.. \& Colliver. J. D., Jr. Dominance of the temporal visual field in letter and line rivalry. Psychonomic Society report. St. Lou is, Missouri, October 31, 1968.

\section{REFERENCES}

Asher, H. Suppression theory of binocular vision. British Journal of Ophthalmology, 1953, 37, 37-49.

Bishop, P. O., \& Henry, G. H. Spatial vision. Annual Revien of Psychology, 1971, 22, 119-160.

Blakemore, C., Carpenter, R. H. S., \& Georgeson, M. S. Lateral inhibition between orientation detectors in the human visual system. Nature, 1970, 228, 37-39.

Boring, E. G. The physical dimensions of consciousness. New York: Dover. 1963. (Originally published, 1933.)

Dodwell. P. C. Visual pattern recognition. New York: Holt. Rinehart. \& Winston, 1970.

Fox. R., \& CHECK, R. Binocular fusion: A test of the suppression theory. Perception \& Psychophysics, 1966, 1, 331-334.

Fox, R., \& McINTYRE, C. Suppression during binocular fusion of complex targets. Psychonomic Science, 1967, 8, 143-144.

Goldstein, A. G. Binocular fusion and contour suppression. Perception \& Psychophysics, 1970, 7, 28-32.

Hochberg, J. E. Contralateral suppression fields of binocular combination. Psychonomic Science, 1964, 1, 157-158.

Hubel, D. H., \& Wiesel, T. N. Receptive fields and functional architecture in two non-striate visual areas of the cat. Journal of Neurophysiology, 1965, 28, 229-289.

Hubel, D. H., \& Wiesel, T. N. Stereoscopic vision in macaque monkey. Nature, 1970, 225, 41-42.

Julesz, B. Foundations of cyclopean perception. Chicago: University of Chicago Press, 1971.

Ka UFMAN, L. Sight and mind: An introduction to visual perception. New York: Oxford University Press, 1974.

LindBerg, D. C. Theories of vision from Al-Kindi to Kepler. Chicago: University of Chicago Press, 1976.

OGLE, K. N. Spatial location through binocular vision. In $\mathrm{H}$. Davson (Ed.), The eye (Vol. 4). New York: Academic Press, 1962.

Ono, H., Angus, R.. \& GRegor, P. Binocular single vision achieved by fusion and suppression. Perception \& Psychophysics, 1977, 21, 513-521.

Pettigrew, J. D. The neurophysiology of binocular vision. Scientific American, 1972, 227, 84-95.

Poulton, E. C. Unwanted range effects from using withinsubjects experimental designs. Psychological Bulletin, 1973. 80, 113-121.

SPERling, G. Binocular vision: A physical and neural theory. American Journal of Psychology, 1970, 83, 464-534.

Verhoeff, F. H. A new theory of binocular vision. Archives of Ophthalmology, 1935, 13, 151-175.

(Received for publication February 24, 1978.) 